\title{
The incidence of anencephalus in the Fylde peninsula 1956-76 and changes in water hardness
}

J. P. BOUND

From the Department of Paediatrics, Victoria Hospital, Blackpool

P. W. HARVEY

From the Department of Pathology, Royal Lancaster Infirmary, Lancaster

D. M. BROOKES AND B.MCA. SAYERS

From the Engineering in Medicine Laboratory, Imperial College, London

SUMMARY In an area which had a high incidence of anencephalus, $3 \cdot 2$ per 1000 births, there was a significant drop to 1.3 per 1000 , below the national average of 1.7 to 1.8 , among conceptions after 1967. In the northern part of the area this drop was greater in summer than winter conceptions, providing additional evidence of a different process underlying case occurrences in the north of the area from that in the south. In 1957-61 there were significantly more births of anencephalic babies in North Fylde than in South Fylde, but both areas were supplied with soft water. From 1962 to 1969 the water changed from soft to slightly hard. Soft water does not appear to be a primary aetiological factor in anencephalus, but hard water may mitigate the effect of other factors.

In a previous paper ${ }^{1}$ we analysed the occurrence of anencephalic stillbirths in the Fylde peninsula of Lancashire, and indicated that there might be a different process underlying case occurrences in the north from that in the south.

Lowe, Roberts, and Lloyd ${ }^{2}$ showed that the mean annual prevalence at birth of congenital malformations of the central nervous system in South Wales was negatively correlated with estimates of the mean total hardness of the related water supplies. Further, they showed a negative correlation between the mean annual perinatal mortality rate from anencephalus and estimates of the mean total hardness of the water supply in 58 county boroughs in England and Wales, but Leck ${ }^{3}$ has drawn attention to the difficulties of interpreting these figures. Using the same data, he showed that prevalence varied less in relation to hardness than to region, suggesting that the latter variation was not secondary to the former. Moreover, Fielding and Smithells, ${ }^{4}$ in a study in south-west Lancashire, concluded that it was unlikely that the nature of the local water supply played any short-term part in the pathogenesis of anencephalus.

\section{Materials and methods}

Anencephalus was studied among babies born to mothers who lived in the most populous part of the
Fylde of Lancashire, the district served by Victoria Hospital, Blackpool. The Fylde is a well-demarcated area approximately $24 \mathrm{~km}$ by $13 \mathrm{~km}$, bounded on three sides by water barriers (Fig. 1). The fourth, landward, border of the district is in sparsely populated country. The population is concentrated on or near the coast and it increased from about 250000 to over 300000 during the period of study. Blackpool is situated about halfway down the west coast. In North Fylde the main urban areas are Fleetwood, Thornton-Cleveleys, and Poulton-le-Fylde, and in South Fylde, Lytham St. Anne's and Kirkham. The proportion of the population over the age of 65 is some $10 \%$ above the national average in Blackpool, Thornton-Cleveleys in the north, and Lytham St. Anne's in the south, and slightly above it in Fleetwood.

The number of live births, stillbirths, and neonatal deaths was notified to us by the medical officers of health. None of the urban areas showed any significant seasonal variation in the total number of births. All case histories of babies dying in the perinatal period were studied and cases of anencephalus noted. Ninety-three per cent of the babies were examined at necropsy, irrespective of place of birth.

The date of the mother's last menstrual period (LMP) rather than the baby's birth date was used for 


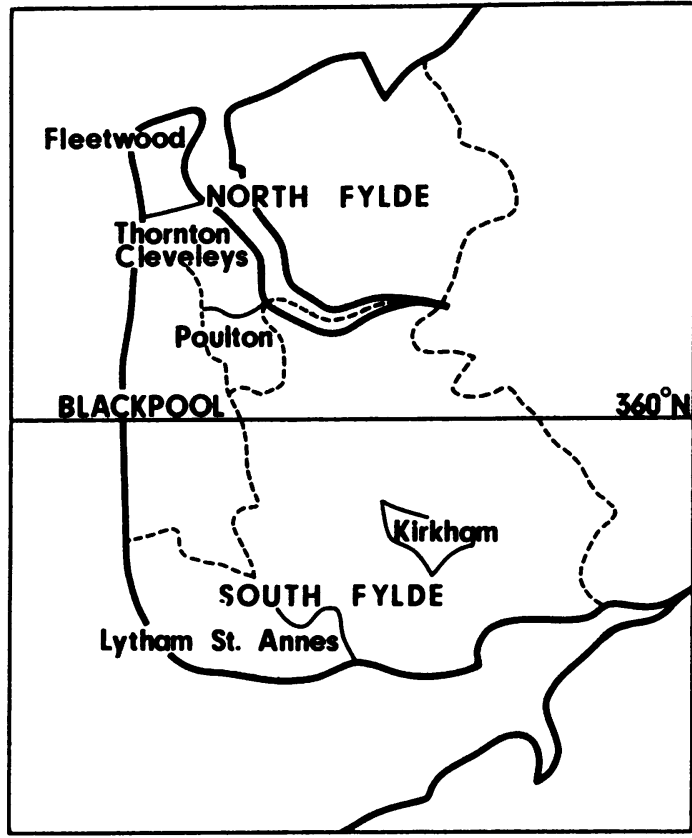

Fig. 1 The Fylde of Lancashire.

the aetiological studies, particularly seasonal influences, because of the wide variation in gestation of anencephalic fetuses. The mothers were visited and their addresses were plotted on a street map. The Ordnance Survey map grid references (to $0.1 \mathrm{~km}$ ) were then determined. The data, consisting of the date of the maternal LMP and the grid references, were then entered through punched cards into the IBM 1800 computer used for all analyses.

Chemical analyses of drinking water, including total hardness, in summer and winter were available from two sampling points in Blackpool. The figures were averages based on about 12 samples at each tap in a year. In 1957 to 1961 analyses for a private house in North Shore showed the hardness of water supplied to North Blackpool, Fleetwood, Thornton-Cleveleys, and Poulton from the Barnacre reservoir. Figures for the water board offices showed the hardness of water supplied to South Blackpool, Lytham St. Anne's, and Kirkham from the Hodder filters. From 1961 to 1971 there were two important changes. Firstly, upland water was supplemented with harder borehole water when necessary, mainly in summer, and, secondly, the pattern of distribution changed considerably. Figures for the water board offices came to indicate the hardness of water supplied to Fleetwood, Thornton-Cleveleys, Lytham St. Anne's, Kirkham, and Blackpool except the central area. Poulton water tended to be softer.
Figures for the private house in North Shore then showed the hardness of water supplied to central Blackpool.

\section{Results}

The incidence of anencephalus among babies born in $1957-61$ was 3.2 per 1000 births. During this period, significantly more cases were born to mothers living in North Fylde than to those in South Fylde (Table 1).

There was a slight fall in incidence in 1962-66, but in the second half of the study period the incidence was significantly lower (Table 2). No therapeutic abortions for anencephalus were carried out during the study period.

To study aetiology, cases were grouped according to the date of the mother's LMP and the northing coordinate of her place of residence at the time of conception. Maternal LMP was classified as summer (May to October) or winter (November to April) and $360 \mathrm{~N}$ was taken as the dividing line between the northern and southern parts of the whole area (Fig. 2). The first 11 summers were tested against the remaining nine (Table 3 ). The drop in cases after 1967 was more pronounced in the northern part of the area although the difference was not significant $(p=0 \cdot 12)$. However, the drop in northern cases was significantly greater in summer than in winter, while for southern cases the distribution did not differ significantly.

Total hardness of water at the two sampling taps is shown in Fig. 3. In 1957-61, when there were significantly more cases of anencephalus born in North Fylde than in South Fylde, the whole area was supplied with soft water throughout the year. In 1962

Table 1 Distribution of anencephalic and total births, 1957-61

\begin{tabular}{lccl}
\hline & $\begin{array}{l}\text { Anencephalic } \\
\text { births }\end{array}$ & $\begin{array}{l}\text { Total } \\
\text { births }\end{array}$ & $\begin{array}{l}\text { Incidence per } \\
\text { I000 births }\end{array}$ \\
\hline North Fylde & 23 & 5286 & 4.4 \\
Blackpool & 29 & 9081 & 3.2 \\
South Fylde & 7 & 3954 & 1.8 \\
Total & 59 & 18321 & 3.2 \\
\hline
\end{tabular}

For North and South Fylde $x^{2}=4.661$ df $p<0.05$.

Table 2 Anencephalic and total births in five-year periods in the Fylde, 1957-76

\begin{tabular}{llll} 
& $\begin{array}{l}\text { Anencephalic } \\
\text { births }\end{array}$ & $\begin{array}{l}\text { Total } \\
\text { births }\end{array}$ & $\begin{array}{l}\text { Incidence per } \\
1000 \text { births }\end{array}$ \\
\hline $1957-61$ & 59 & 18321 & $3 \cdot 2$ \\
$1962-66$ & 53 & 20827 & $2 \cdot 5$ \\
$1967-71$ & 24 & 19132 & $1 \cdot 3$ \\
$1972-76$ & 20 & 15281 & $1 \cdot 3$ \\
\hline
\end{tabular}

$x^{2}=23.703$ df $p<0.001$. 

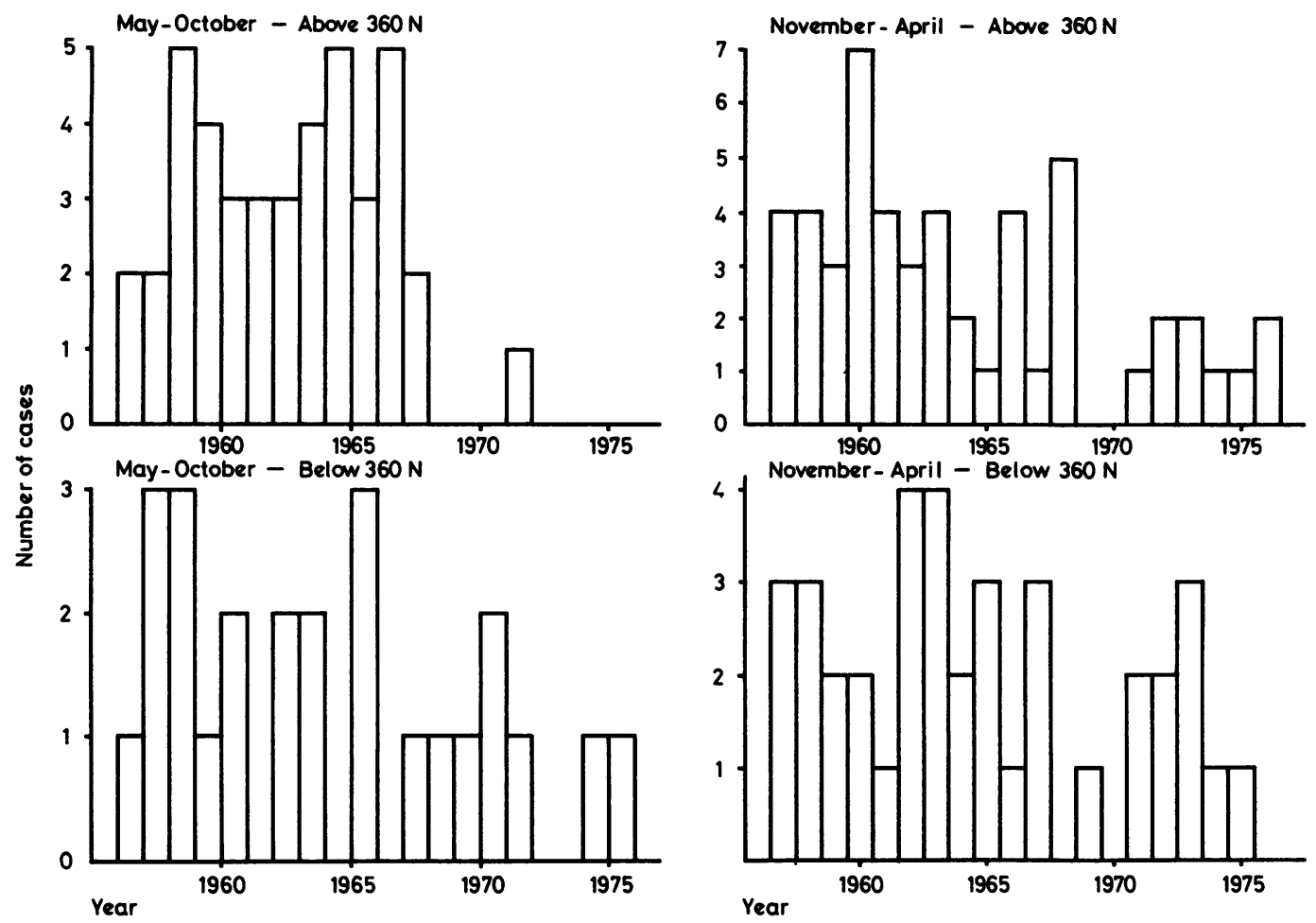

Fig. 2 Seasonal effects in the north and south parts of the area.

Table 3 Distribution of anencephalic babies in the north and south parts of the region by summer (May-October) and winter (November-April) conceptions, 1956-76

\begin{tabular}{lllll}
\hline & & $\begin{array}{l}\text { May 1956- } \\
\text { April 1967 }\end{array}$ & $\begin{array}{c}\text { May 1967- } \\
\text { April 1976 }\end{array}$ & Total \\
\hline North of 360N & Summer & 39 & 3 & 42 \\
& Winter & 37 & 14 & 51 \\
& Total & 76 & 17 & 93 \\
\hline$x^{2}=6.36 \mathrm{p}=0.012$. & & & \\
South of 360N & Summer & 17 & 8 & 25 \\
& Winter & 28 & 10 & 38 \\
& Total & 45 & 18 & 63 \\
\hline
\end{tabular}

$x^{2}=0.24$ NS.

the hardness of summer water began to increase and after 1967-when the significant drop in incidence of anencephalus began - it approached, and in 1969 reached, the slightly hard category (total hardness 100 to $150 \mathrm{ppm}$ ). After 1971 there was a slight fall in the hardness of water supplied to central Blackpool. A temporary increase in the hardness of winter water in 1972 and 1973 was not associated with any further decline in the incidence of anencephalus, as shown in the graphs of Fig. 2.

\section{Discussion}

During the first five years of our study the incidence of anencephalus was high, and comparable with rates reported from South Wales during 1956-62.5 After 1968, births of anencephalic babies in the Fylde fell below national levels which showed little change at the time, varying between 1.7 and 1.8 per 1000 births. ${ }^{6}$ The north-west region showed a slow decline in incidence from 1961-72 but the rate was slightly higher in 1969-70 than in 1967-8. It seems likely that a local environmental change in the Fylde occurred at that time.

Previously we presented evidence that a different process could be generating cases in the north of our region from that in the south. ${ }^{1}$ Data presented in this paper provide additional evidence that this is so. The post-1967 drop in conceptions of anencephalic babies in the north was greater in summer than winter, while in the south there was no significant seasonal difference. It seems that cases of anencephalus are generated by more than one factor even in a comparatively small area of the country.

In view of conflicting reports of an association between hardness of water supplies and the incidence 


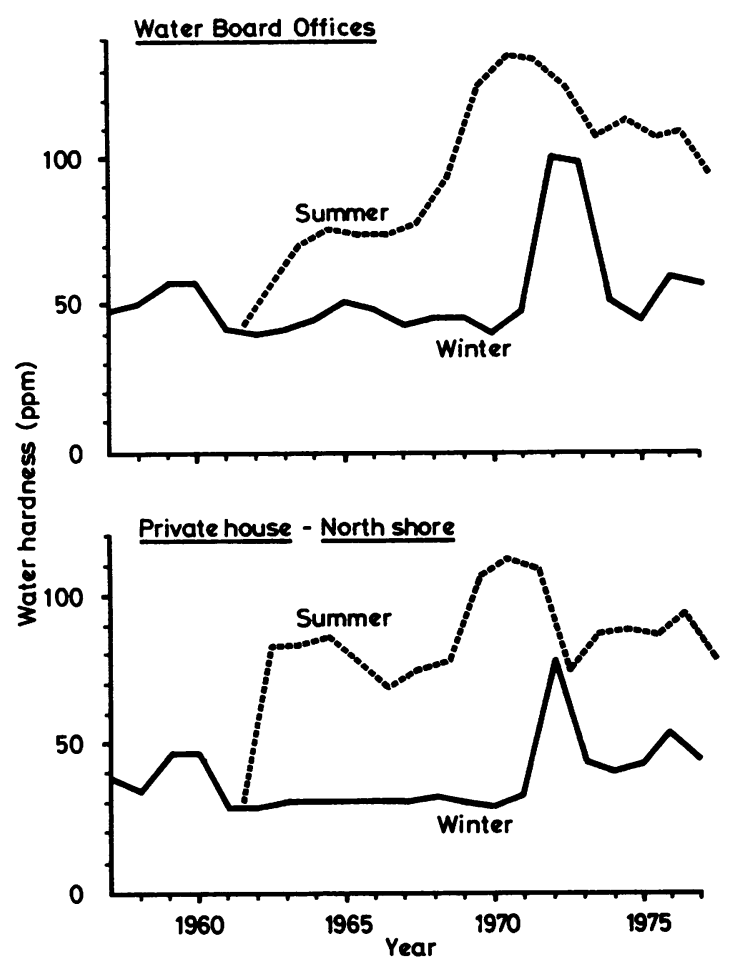

Fig. 3 Variations in water hardness.

of anencephalus, we examined our data for evidence that would confirm or refute the claims. During 1957-61 significantly more cases were born to mothers living in North Fylde than in South Fylde. Throughout this time the whole area was supplied with soft water. This seemed to rule out soft water as a primary factor in the aetiology of anencephalus. However, the drop in cases after 1967 was associated with increased hardness of the water in summer, and this raises the possibility that hard water may mitigate the effect of other aetiological factors.

If hard water has an effect, it may be because of a trace element. There is evidence suggesting an association between the occurrence of congenital malformations and deficiency of certain trace elements. Hambidge, Neldner, and Walravens ${ }^{7}$ reviewed reports of one abortion and two congenital abnormalities, one of them anencephalus, among seven pregnancies in three women with acrodermatitis enteropathica, which provided strong evidence that zinc deficiency was teratogenic. Morton, Elwood, and Abernethy ${ }^{8}$ found that central nervous system malformation rates in South Wales had negative correlations with copper and barium levels in tap water.

A recent report has suggested that periconceptional vitamin supplementation can prevent some neural tube defects. ${ }^{9}$ However, even if the value of the preparation used in the trial is confirmed, it also contains added minerals.

Our findings would be compatible with an effect from a trace element when the annual intake reached a certain level. After this, any further increase would show no effect. This could explain why the temporary increase in hardness of winter water in the Fylde in 1972 and 1973 had no influence on the incidence of anencephalus, which had already fallen below the national average.

If it is correct that soft water is not a primary but a secondary factor in the aetiology of anencephalus, the conflicting reports in the literature might be explained. Leck, ${ }^{10}$ reviewing the causation of neural tube defects, suggested that it might well be that environmental influences were multiple factors with individually small but cumulative effects. Our findings suggest that soft water is one such factor.

We are indebted to the late Mr. F. Law, Engineer, Fylde Water Board, and to Mr. D. J. Hall, Assistant Divisional Scientist, Ribble Division, North West Water Authority, for data on the water supply.

Reprints from Dr. J. P. Bound, Victoria Hospital, Whinney Heys Road, Blackpool FY3 8NR.

\section{References}

'Sayers BMcA, Segal SD, Henshall WR, Bound JP, Harvey PW. Analysis of the occurrence of anencephalic stillbirths in the Fylde Peninsula, 1956-1967. Med Inform 1978; 3: 51-68.

'Lowe CR, Roberts CJ, Lloyd S. Malformations of central nervous system and softness of local water supplies. $\mathrm{Br}$ Med J 1971; ii: 357-61.

${ }^{2}$ Leck I. Correlations of malformation frequency with environmental and genetic attributes in man. In: Wilson JG, Fraser FC, ed. Handbook of teratology volume 3. New York: Plenum, 1977: 243-324.

4Fielding DW, Smithells RW. Anencephalus and water hardness in South-West Lancashire. Br J Prev Soc Med 1971; 25: 217-9.

s Laurence KM, Carter CO, David PA. Major central nervous system malformations in South Wales. Br J Prev Soc Med 1967; 21: 146-60.

- Rogers SC, Weatherall JAC. Anencephalus, spina bifida and congenital hydrocephalus. England and Wales 1964-1972. Office of Population Censuses and Surveys. Studies on Medical and Population Subjects No. 32. London: HMSO, 1976.

${ }^{7}$ Hambidge KM, Neldner KH, Walravens PA. Zinc, acrodermatitis enteropathica and congenital malformations. Lancet 1975; i: 577-8.

- Morton MS, Elwood PC, Abernethy M. Trace elements in water and congenital malformations of the central nervous system in South Wales. BrJ Prev Soc Med 1976; 30: 36-9.

- Smithells RW, Sheppard S, Schorah CJ et al. Possible prevention of neural-tube defects by periconceptional vitamin supplementation. Lancet 1980; i: 339-40.

${ }^{10}$ Leck I. Causation of neural tube defects: clues from epidemiology. Br Med Bull 1974; 30: 158-63. 